\title{
Changes in molecular composition of slow and passive pools of Haplic Chernozems during restoration organic matter storage
}

Kholodov V.A. ${ }^{1}$, Farkhodov Yu.R. ${ }^{1,2}$, Yaroslavtseva N.V. ${ }^{1}$

${ }^{1}$ Dokuchaev Soil Science Institute, Moscow, Russia, vkholod@mail.ru

${ }^{2}$ Lomonosov Moscow State University

doi: 10.36291/HIT.2019.kholodov.032

An active, slow and passive pools of soil organic matter (SOM) plays different roles in soil media. Wherein their closely link each other by degradation and restoration processes in soils. The behavior of active pool of SOM during soil restoration more or less is known. Herewith features of restoration slow and passive pools not clear enough.

Thermolabile organic matter is a part of SOM, which volatilized at heating up to $350^{\circ} \mathrm{C}$. Content of thermolabile organic matter in soil closely correlated with active $\mathrm{C}$ pool. In contrast thermostable one are volatilized at temperature from 350 to $600{ }^{\circ} \mathrm{C}$ and can be attributed to slow and passive pools of SOM. In this connection molecular structure both thermostable and thermostable parts of SOM can be studied by double-shoot pyrolysis combine with gas chromatography mass-spectrometry (double-shot Py-GC MS).

Goal of this work was to investigation of changes of molecular composition of slow and passive pools of Haplic Chernozems (Loamic, Pachic) during restoration after total degradation of organic matter without the receipt of plant residues.

Objects of this work were Haplic Chernozems of long-term field experiments: permanent tilled bare fallow since 1964 (total degradation of SOM), unmanaged fallow since 1998 after permanent tilled bare fallow since 1964 (reclaimed soil) and annually mown steppe (undisturbed soil).

Molecular set of slow pool was estimated by second step of pyrolysis Py-GC MS of humic acids are isolated from Chernozems. The passive pool composition was evaluated by second step of Py-GC MS of whole soil.

Slow and passive pools of degraded Chernozems have height abundance of not available for plants nitrogen compounds. In process of restoration of Chernozems in slow pools polysaccharides accumulate. In passive pool increased content of alkanes and aromatic structures.

Acknowledgements. This work has been supported by Russian Science Fund, project \# 19-16-00053. 